\title{
Statistical Distribution of Streambed Vertical Hydraulic Conductivity along Main Stream of WeiHe River, China
}

\author{
Nan Zhang ${ }^{1, *}$, Daoxi Wang ${ }^{1}$, Feng Huang ${ }^{2}$, Huijuan Yin ${ }^{1}$, Pan Zhang ${ }^{1}$ and \\ Xinwei Guo ${ }^{1}$ \\ ${ }^{1}$ Yellow River Institute of Hydraulic Research, Zhengzhou, China. \\ ${ }^{2}$ College of Water Resources, Hohai University, Nanjing, China. \\ *zhangnan19810202@126.com
}

\begin{abstract}
Streambed vertical hydraulic conductivity (Kv) plays an important role in understanding the water exchange and contaminant transport system between river streams and groundwater flows. The tests were conducted at 464 test points of 10 test sites to measure the vertical hydraulic conductivity $(\mathrm{Kv})$ for the streambed by using the falling-head standpipe permeameter. The traditional statistics and geostatistics methods were applied to determine the spatial variability of hydraulic conductivity. The $\mathrm{Kv}$ values range from 0.01 to $61.32 \mathrm{~m} / \mathrm{d}$ with the mean value of $4.62 \mathrm{~m} / \mathrm{d}$, the thermal method shows higher discharge rates about in $48 \mathrm{~cm} \sim 51 \mathrm{~cm}$ depth. In the winter test groundwater recharge was more frequently than in the summer test. The $\mathrm{Kv}$ values of streambed sediment decreases with increasing depth, different sediment particle size is mainly influence factors. At the same test site, the difference in flux can be explained by different characters of sediment.
\end{abstract}

Keywords: water exchange; Contaminant transport; Hydraulic conduction.

\section{Introduction}

Hydraulic conductivity is essential for modeling the water flow and transport processes in the subsurface (Qifei Niu et al.) and is one of the basic measures of the water flow in the ground (Anna Ilek, 2014). Streambed vertical hydraulic conductivity (Kv) plays an important role in understanding and quantifying the stream-aquifer interactions (Cheng Cheng et al., 2011). Chen and Shu (2002) reported that a higher streambed $\mathrm{Kv}$ induces a higher rate of stream depletion due to the groundwater withdrawal; Salehin (2004) found that the spatial variation of streambed Kv values can be jointly reflected by the exchange process of surface-groundwater, the solute retention and the mixing times. Therefore, streambed $\mathrm{Kv}$ is also a necessary parameter in numerical modeling of stream-aquifer interactions.

The temporal and spatial variations of streambed Kv have been discussed and analyzed by many researchers over the past 15 years. Previous research discussed different methods for estimating the streambed Kv, which include the pumping test (Ibrahimu Chikira Mjemah et al., 2009), grain-size analysis (Rosa Di Maio et al., 2015), trace method (Valentina Carucci, 2012), and permeameter test (Md Rajibul Karim, S.C.R. Lo, 2015). In general, grain-size analysis cannot evaluate the anisotropy of $\mathrm{Kv}$ values as the sediment structure is destroyed during sampling (Cheng and Chen, 2007). The streambed $\mathrm{Kv}$ values can be obtained by using permeameter test which is more accurate than grainsize analysis and less expensive than pumping test. Although the trace method is an advanced way, it is too costly and trial process is more accurate than other methods.

The Weihe River is a vital river of Shaanxi Province, China, it influences the vicissitude of social and economy in Shaanxi Province directly (Song, 2013). The research of the spatial variability of streambed Kv value of the Weihe River is significantly important to analyze the health of the river system. In recent years, field experiments of streambed $\mathrm{Kv}$ values have received high attention in the international community and studied extensively. Lai et al. (2013) analyzed the rules and reasons of the vertical hydraulic conductivity of sediments changes with depth in Weihe River. Sediment samples in the study sites were taken and particle size analysis of the samples was carried out by Zhang et al. (2013), however, they did not analyze the statistical distribution of streambed Kv at distant sites along the river. In this paper, we determine the statistical distribution and spatial variation of streambed $\mathrm{Kv}$ values at 10 test sites along the main stream of the Weihe River. A detailed statistical 
distribution of streambed $\mathrm{Kv}$ along a $170 \mathrm{~km}$ segment of the main stream of the Weihe River from Meixian to Huaxian is estimated in this research, and the possible influences of tributary in controlling streambed permeability at a large scale are analyzed.

\section{Materials and Methods}

\subsection{Study Area}

Weihe River is located in the main stream of the Weihe River from Meixian to Huaxian (Fig.1). The stream stage and stream flow rate in the study area were collected from the four gauges stations (A to D in Fig. 1). The average stream discharge and stream level of these four gauges stations are shown in Table 1. Besides, the Jinghe River may bring fine-grained sediments from tributary.

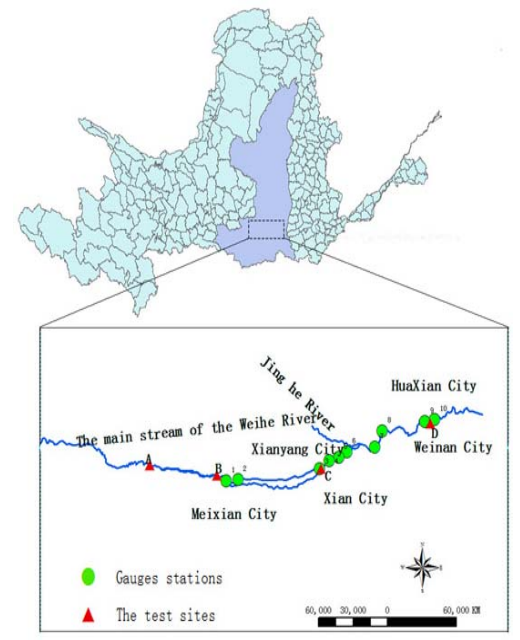

Fig. 1 Map of study area and tests sites (1 to

10), dots represent test sites, triangles represent gauges stations

Table 1. Average stream discharge and stream level in four gauges stations

\begin{tabular}{ccccc}
\hline $\begin{array}{c}\text { Station } \\
\text { location }\end{array}$ & $\begin{array}{c}\text { Longitude and } \\
\text { Latitude }\end{array}$ & $\begin{array}{c}\text { Mean stream discharge } \\
\left(\mathrm{m}^{3} / \mathrm{s}\right)\end{array}$ & $\begin{array}{c}\text { Mean stream level } \\
(\mathrm{m})\end{array}$ & Date range \\
\hline $\mathrm{A}$ & $107.05,34.38$ & 85 & 493 & $2004-2014$ \\
$\mathrm{~B}$ & $107.7,34.30$ & 158 & 382 & $2004-2014$ \\
$\mathrm{C}$ & $108.7,34.32$ & 234 & 352 & $2004-2014$ \\
$\mathrm{D}$ & $109.77,34.58$ & 257 & 336 & $2004-2014$ \\
\hline
\end{tabular}

\subsection{Methods}

We apply an in-situ permeability coefficient test, using the falling head method by inserting transparent polycarbonate standpipes into sediments (Fig. 2). The pipes, staked vertically into the streambed sediments, are $160 \mathrm{~cm}$ in length, $1-\mathrm{mm}$ thick and $6 \mathrm{~cm}$ in diameter. After being pressed into a desired depth, the pipe was kept in the streambed for an appropriate time in order to allow the hydraulic head inside the tube to reach equilibrium to attune to the compaction of the streambed sediments inside the pipe (Chen, 2009). After the equilibrium was reached, the surface water level over the streambed surface was considered as the initial hydraulic head at the test point. Water was then added from the top of the pipe. Any group of data from the in-situ permeability coefficient tests can be used to calculate the Kv value using the equation of Hvorslev (1951):

$$
k v=\frac{\frac{\pi \mathrm{D}}{11 \mathrm{~m}}+L v}{\left(t_{2}-t_{1}\right)} \ln \left(h_{1} / h_{2}\right)
$$




$$
m=\sqrt{k_{h} / k_{v}}
$$

Where Lv is the length of sediment in the tube; $h 1$ and $h 2$ are hydraulic head inside the pipe measured at times of $\mathrm{t} 1$ and $\mathrm{t} 2, \mathrm{D}$ is the inner diameter of the pipe, $\mathrm{Kh}$ is the horizontal hydraulic conductivity of the streambed sediment around the base of the sediment core.

Test points in study site 2, which measure the streambed Kv values, are shown in Fig. 3.

\section{Results and Analyses}

\subsection{Streambed Kv Values in the WeiHe River}

Table 2. Average streambed Kv (vertical hydraulic conductivity) and Lv (the length of sediment in the tube), water depth and grid spacing at the ten test sites

\begin{tabular}{|c|c|c|c|c|c|c|c|c|}
\hline \multicolumn{9}{|c|}{ Grid spacing } \\
\hline Test sites & Test date & $\begin{array}{l}\text { Number } \\
\text { of tests }\end{array}$ & $\begin{array}{c}\text { Of rows, } \\
\text { distance } \\
\text { between } \\
\text { each test } \\
\text { point }\end{array}$ & $\begin{array}{c}\text { Of } \\
\text { columns, } \\
\text { distance } \\
\text { between } \\
\text { each test } \\
\text { point }\end{array}$ & $\begin{array}{c}\text { Average } \\
L_{v}(\mathrm{~cm})\end{array}$ & $\begin{array}{l}\text { Average } \\
K_{v}(\mathrm{~m} / \mathrm{d})\end{array}$ & $\begin{array}{c}\text { Standard } \\
\text { deviation } \\
\text { of } K_{v}\end{array}$ & $\begin{array}{l}\text { Average } \\
\text { water } \\
\text { depth } \\
(\mathrm{cm})\end{array}$ \\
\hline 1(Meixian) & $\begin{array}{c}\text { July } 8 \text {, } \\
2014, \\
\text { December } \\
20,2014\end{array}$ & 26 & $5-8 m$ & $3 \mathrm{~m}$ & 48.3 & 0.88 & 1.35 & 45 \\
\hline 2(Meixian) & $\begin{array}{c}\text { July } 8 \text {, } \\
2014, \\
\text { December } \\
20,2014\end{array}$ & 26 & $5-8 m$ & $3 \mathrm{~m}$ & 52 & 0.50 & 0.64 & 56 \\
\hline 3(Xianyang) & $\begin{array}{c}\text { December } \\
22,2014\end{array}$ & 48 & $6-8 \mathrm{~m}$ & $4 \mathrm{~m}$ & 50.4 & 0.18 & 0.18 & 71.67 \\
\hline 4(Xianyang) & $\begin{array}{c}\text { December } \\
22,2014\end{array}$ & 48 & $6-8 \mathrm{~m}$ & $4 \mathrm{~m}$ & 48.5 & 0.22 & 0.29 & 50.50 \\
\hline 5(Xian) & $\begin{array}{c}\text { June } \\
26,2014, \\
\text { December } \\
24,2014\end{array}$ & 50 & $6 \mathrm{~m}$ & $3 \mathrm{~m}$ & 50.5 & 10.62 & 9.64 & 34 \\
\hline 6(Xian) & $\begin{array}{c}\text { June } \\
26,2014 \text {, } \\
\text { December } \\
24,2014\end{array}$ & 50 & $6 \mathrm{~m}$ & $3 \mathrm{~m}$ & 47.2 & 0.66 & 0.17 & 69.5 \\
\hline $\begin{array}{l}\text { 7(Lin } \\
\text { Tong) }\end{array}$ & $\begin{array}{c}\text { December } \\
26,2014\end{array}$ & 64 & $6-8 \mathrm{~m}$ & $5 \mathrm{~m}$ & 48.5 & 0.36 & 0.54 & 71.33 \\
\hline $\begin{array}{l}8(\mathrm{Lin} \\
\text { Tong) }\end{array}$ & $\begin{array}{c}\text { December } \\
26,2014\end{array}$ & 64 & $6-8 \mathrm{~m}$ & $5 \mathrm{~m}$ & 51.2 & 0.64 & 1.20 & 41.75 \\
\hline 9(Huaxian) & $\begin{array}{c}\text { June } \\
27,2014 ; \\
\text { December } \\
29,2014\end{array}$ & 44 & $5 \mathrm{~m}$ & $2 \mathrm{~m}$ & 49.5 & 1.30 & 1.75 & 52.75 \\
\hline 10(Huaxian) & $\begin{array}{c}\text { June } \\
27,2014 ; \\
\text { December } \\
29,2014\end{array}$ & 44 & $5 \mathrm{~m}$ & $2 \mathrm{~m}$ & 50.4 & 0.18 & 0.13 & 41.67 \\
\hline
\end{tabular}


Chen (2004) indicated that increasing Lv could reduce the overestimation of Kv. Therefore, in this study, the number of permeameter tests, the grid spacing at the ten test sites (site 1 to 10) from Meixian(sites 1 and 2) to Huaxian(sites 9 and 10) in the Weihe River, are shown in the Table 2.

In Table 2, the average Lv from sites 1 to 10 in this study is below $60 \mathrm{~cm}$. At site 5 , the mean $\mathrm{Kv}$ is different to other sites, it was influenced by the tributary. Large standard deviation of $\mathrm{Kv}$ indicates that the stream Kv values can vary significantly within the same site, especially at site 5. On the whole, the standard deviations of Kv values at the ten sites were slightly different. This difference is probably induced by (1) a large number of permeameter tests conducted at the ten new sites in the study and (2) the reason that the tests for these ten sites were conducted in regularly but closer spaced compared to the tests along the across channel transect for 1 to 4 . It can be anticipated that large heterogeneity in streambeds exists along a transect across the channel and less heterogeneity in streambeds of smaller scale plots.

\subsection{Traditional Statistical Research on Spatial Variability of Permeability Coefficient}

The thickness of tested sediment is between 34 and $58.9 \mathrm{~cm}$ in these ten sites (Table 3 ). The $\mathrm{Kv}$ values range from 0.55 to $61.32 \mathrm{~m} / \mathrm{d}$ in sites 3 and 4 . The $\mathrm{Kv}$ values ranged from 0.03 to $6.21 \mathrm{~m} / \mathrm{d}$ in sites 5 and 6 . The $\mathrm{Kv}$ values ranged from 0.01 to $1.9 \mathrm{~m} / \mathrm{d}$ in sites 9 and 10 . The $\mathrm{Kv}$ value ranged from 0.02 to $2.3 \mathrm{~m} / \mathrm{d}$ in sites 7 and 8 . It can be seen from the statistical data that the largest frequency distribution of $\mathrm{Kv}$ value is $0 \sim 5 \mathrm{~m} / \mathrm{d}$ (Table 3, Fig. 4). The spatial distribution of the sediment hydraulic conductivity indicates that the $\mathrm{Kv}$ is the largest in site 5 and 6, the second largest $\mathrm{Kv}$ is in sites 3 and 4, and it is the smallest in site 9 and 10 (Fig. 5).

Table 3. Thickness of sediment and corresponding Kv value

\begin{tabular}{cccccc}
\hline \multirow{2}{*}{ Site } & \multicolumn{2}{c}{ Thickness of sediment $(\mathrm{cm})$} & \multicolumn{3}{c}{$K_{v}(\mathrm{~m} / \mathrm{d})$} \\
& Range & Mean & Range & Mean & Coefficient of variation \\
\hline 1 and 2 & $34 \sim 57$ & 49.0 & $0.02 \sim 1.17$ & 0.35 & 0.95 \\
3 and 4 & $40.3 \sim 58.9$ & 46.1 & $0.55 \sim 61.32$ & 18.88 & 1.12 \\
5 and 6 & $40.9 \sim 57$ & 47.9 & $0.03 \sim 6.21$ & 2.49 & 1.49 \\
7 and 8 & $37 \sim 42$ & 39.5 & $0.02 \sim 2.3$ & 0.30 & 0.59 \\
9 and 10 & $35 \sim 48$ & 38.7 & $0.01 \sim 1.9$ & 1.10 & 0.89 \\
\hline
\end{tabular}

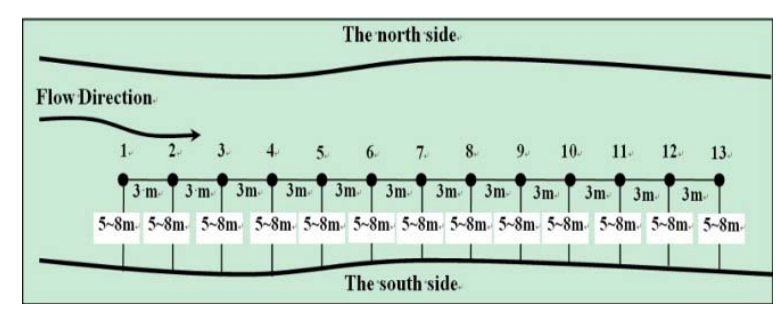

Fig. 3 Sketch map of test points.
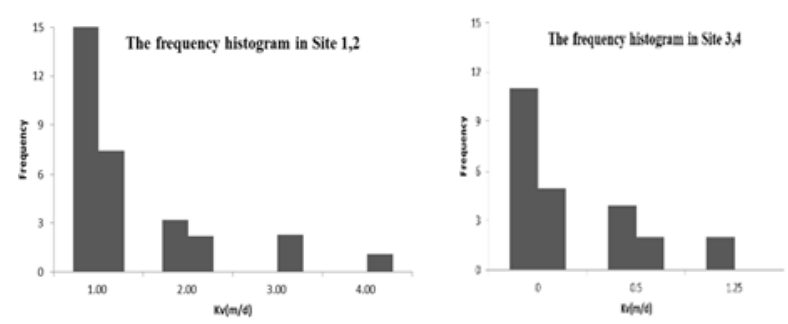

Fig. 5 Frequency histogram in each study area

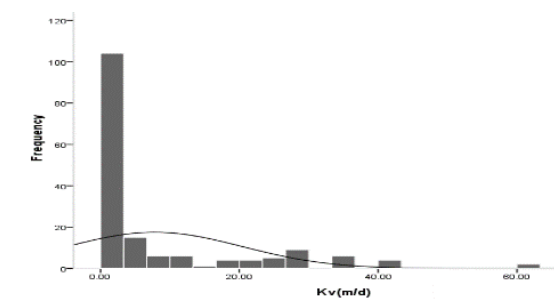

Fig. 4 Frequency histogram of $(\mathrm{Kv})$ in each site
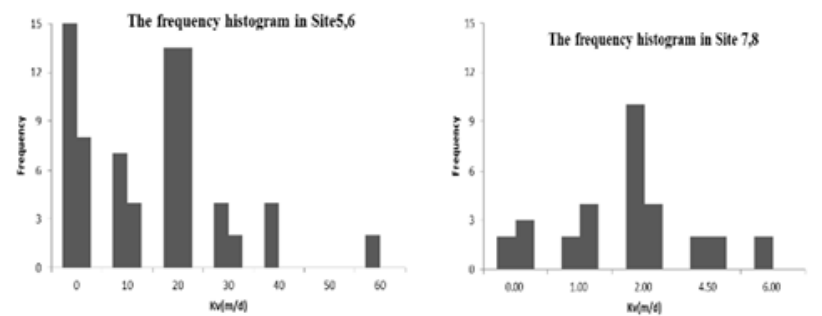

The coefficient of variation reflects the dispersion around the, which indicates the low degree when $\mathrm{Cv}<0.1$, the medium degree when $0.1 \leq \mathrm{Cv} \leq 1.0$, and the high degree when $\mathrm{Cv}>1.0$. The $\mathrm{Cv}$ values of the 5 study sites range from $0.59 \%$ to $1.49 \%$, indicating that the $\mathrm{Kv}$ of river sediment varies in 
different sections of the river. The spatial variability in site $1,2,9,10,3$ and 4 is moderate and is mainly influenced by the environmental factors. The spatial variability in site 5, 6, 7 and 8 is significant, mainly influenced by the sediment structure, and rarely influenced by the environmental factors.

\subsection{Characteristics of Spatial Variation of Permeability Coefficient}

Based on ARCGIS, the Kriging was applied to interpolate values for numerically analysing the permeability coefficient of the 5 study sites and processing of the Kv values. The positive direction of $\mathrm{y}$ axis is the direction of river flows, the $\mathrm{y}$ axis is approximately the location of river bank when $\mathrm{x}$ equals to -2 . The river flows from south to north in site 3 and 4, and flows from west to east in other sites. Along the flow direction, the Kv values in site 3 and 4 decrease gradually, while the values increase gradually in site $9,1,7,8,5$ and 6 . In sites 1 and 2, the $\mathrm{Kv}$ values show a complex variation pattern, which increase firstly and then decrease (Fig. 6).
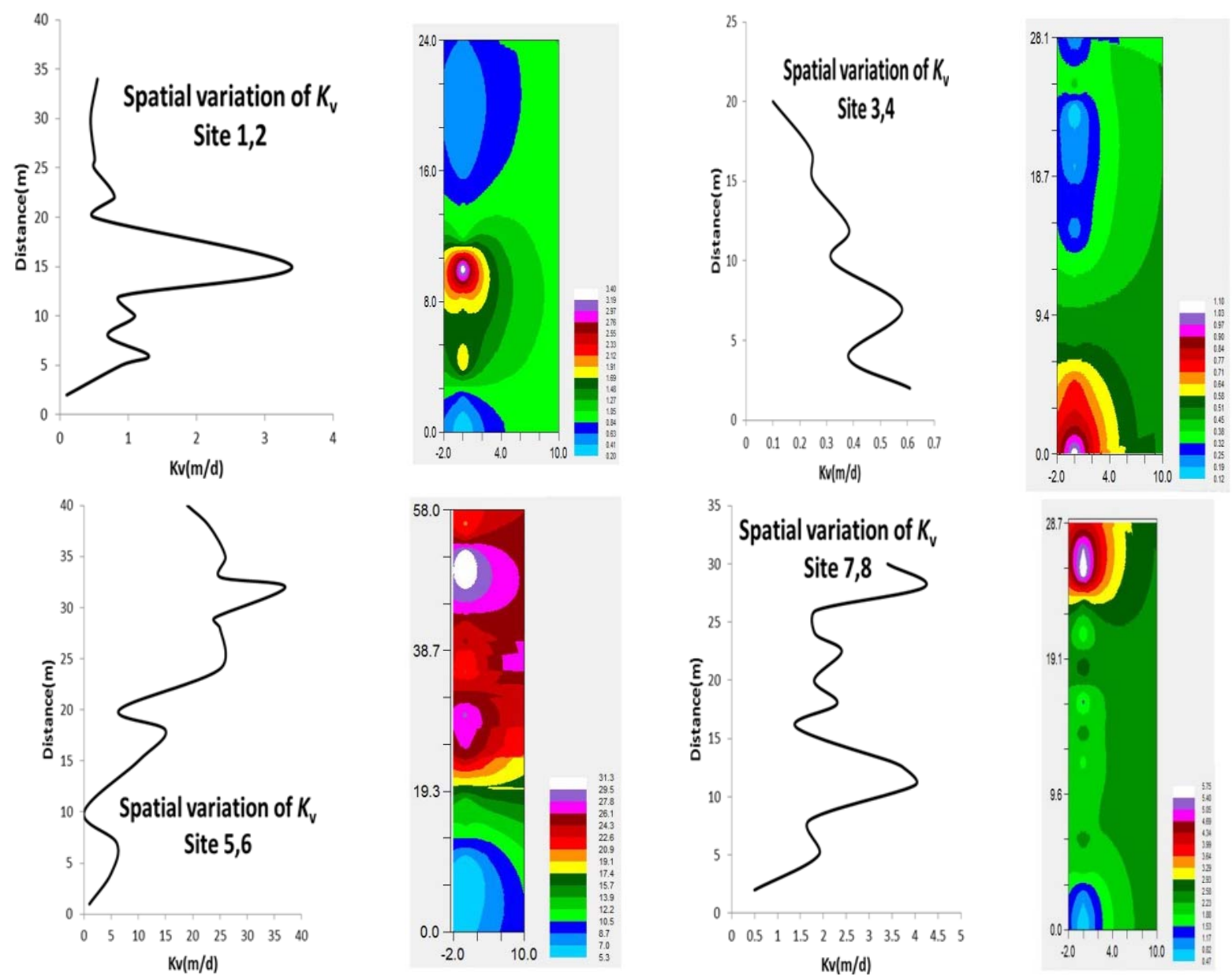

Fig. 6 partial variation of $\mathrm{Kv}$

The sediment was grouped by the Pearson Correlation Coefficient and the correlation coefficient (Table 4) between grain size and permeability coefficient of streambed. There is a significant positive correlation between $\mathrm{Kv}$ values and the sand content and gravel content in sediments. The positive correlation indicates that $\mathrm{Kv}$ increases with the increase of sand content and gravel content. There is a significant negative correlation between the $\mathrm{Kv}$ values and clay content, indicating that $\mathrm{Kv}$ decreases with the increase of clay content. 
Table 4. Correlation coefficient between components of sediment and permeability coefficient of streambed

\begin{tabular}{ccl}
\hline Main components & correlation coefficient & significance \\
\hline Clay & -0.863 & Significant $(0.05)$ \\
Sandy & 0.801 & significant $(0.05)$ \\
Gravel & 0.921 & significant $(0.05)$ \\
\hline
\end{tabular}

In generally, the porosity is better when the grain is larger, resulting in the unobstructed water flow and the increased Kv value. The larger grain has a better porosity so that water flows through it more easily. Sandy sediments have better porosities. So, the Kv values are not only influenced by the sediments grain size, but also influenced by the components of sediments. Sites 3 and 4 are influenced by a bridge and an artificial lake in the downstream of the river, where the sediments contain a lot of silty sand, clay and sludge, and consequently the $\mathrm{Kv}$ value is relatively small. The main components of sediments are sand and bigger grain, so the Kv values are large. The river channel at sites 1 and 2 have many tributaries and floodplain areas, the suspended loads are transferred to the downstream and the sediment deposition is rather severe.

Table 5. Each test point composition of sediment weight percentage Unit: \%

\begin{tabular}{cccc}
\hline Test point & Mass percent of silty sand and clay & Mass percent of sand & Mass percent of gravel \\
\hline 1,2 & 31.6 & 67.9 & 0.5 \\
3,4 & 35.74 & 64.15 & 0.11 \\
5,6 & 0.51 & 92.43 & 7.07 \\
7,8 & 15.19 & 84.32 & 0.49 \\
\hline
\end{tabular}

According to the length of L1 and L2, the sediment samples should be separated into different sample bags, and the grading analysis should be done in the soil lab. The samples should be classified into 17 grades by using sieve method, and the accumulated mass percent of sediment should be computed in the grading analysis. The smallest grain size is $0.075 \mathrm{~mm}$ and the largest grain size is 1.2 $\mathrm{cm}$. The sediment grain size, which is smaller than $0.075 \mathrm{~mm}$, is silty sand and clay, while the grain size is larger than $2 \mathrm{~mm}$, it is gravel, while the rest is sand. Based on the grading analysis, the main component of river bed sediment in site 1, 2, 5, 6, 7, 8 is sand, and the main component of river bed sediment in site 3, 4 is silty sand and clay. The gravel is less for the four-study section, which means that, $\mathrm{Lv}$ is able to indicate the minimum vertical permeability coefficient if and the decrease of $\mathrm{Kv}$ according to increasing depth is not caused by sediment grading distribution, if it is about $50 \mathrm{~cm}$.

\section{Discussion}

For most sediment cores, the thickness of sediment is much shorter than the length of the tube, part of large size particles might be slipped away from the tube during the sediment coring, as a result, the values of some reach for the sediments formed in the tube is larger. Furthermore, the length of the core influence on the test values. Moreover, when the hollow tube is pressed into the streambed, it can cause compaction of the sediment inside the tube. This compaction can disturbance the values of the permeability coefficient Kv. If a large compaction of the streambed indeed occurred the test results was performed at another nearby location. Also, this issue is our further work to think about.

The field test is a lack of deep water test due to the limitation of river length and water depth. The test point cannot be the same for summer and winter seasons, the test was only carried out for the same distance in the same river. Influenced by the water level, the relative locations between the test point and the river bank are the same, while the absolute locations are different. Due to the fluctuation of water level during the test, there are many field test limitations, and the measurements are less. Further research should be done by considering and making comparison with the other test and analysis methods. 


\section{Conclusion}

Applying the falling-head standpipe permeameter, the tests were conducted at 464 points in 10 sites to measure the vertical hydraulic conductivity $(\mathrm{Kv})$ for the streambed. The $\mathrm{Kv}$ values range from 0.01 to $61.32 \mathrm{~m} / \mathrm{d}$ with the mean of $4.62 \mathrm{~m} / \mathrm{d}$. The maximum frequency is distributed at $0 \sim 5 \mathrm{~m} / \mathrm{d}$. The mean $\mathrm{Kv}$ values are $0.35 \mathrm{~m} / \mathrm{d}, 18.88 \mathrm{~m} / \mathrm{d}, 2.49 \mathrm{~m} / \mathrm{d}, 1.1 \mathrm{~m} / \mathrm{d}$ and $0.03 \mathrm{~m} / \mathrm{d}$ in sites 3, 5, 6, 7, 8, 1,2, 9 and 10, respectively. The spatial distribution of the sediment hydraulic conductivity indicates that the $\mathrm{Kv}$ is the largest in sites 5 and 6, followed by sites 7, 8, 1, 2, 9, 10, 3 and 4. Along the flow direction, the Kv values in sites 3 and 4 gradually decrease, and increase gradually, in sites 9 and 10. The spatial and seasonal variability patterns of the stream water and groundwater interaction are illustrated. The thermal method shows higher discharge rates about in $48 \mathrm{~cm} \sim 51 \mathrm{~cm}$ depth both in the two tests. The surface water was mainly recharged by ground water in the two tests in every test sites. Except site 1, 2 , a higher flux was observed in other sites in the winter test than in the second summer test. And it indicated that in the winter test groundwater recharge was more frequently than in the summer test. According to the values of flux, the sequence is from largest to smallest as follows: sites $7,8,3,4,9,10,5,6,1,2$ in the winter test and 1,2,9,10,3,4,7,8,5,6 in the summer test, this is similar with the results of Lai Wen-li et al. (2013), Weiwei Jiang et al. (2015). The Kv values of streambed sediment decreases with increasing depth, different sediment particle size is mainly influence factors. This spatial difference shows the importance of the local geomorphology and to a lesser extent the hydrogeologic setting on hyporheic flux exchange in the river. As the composition of the riverbed sediments is relatively uniform, the difference in flux can be explained by different hydraulic gradients, heterogeneity of the underlying geologic layers, the curvature of the bank of the river, the water depth of test sites and so on. At the same test site, the difference in flux can be explained by different characters of sediment.

\section{Acknowledgments}

This research was financially supported by National key research and development plan No.2017YFC0403505 and the research of National Natural Science Foundation of China (NSFC) No.51309107, 41401011, 51409110. We also thankful to anonymous reviewer for his constructive comments in the manuscript review.

\section{References}

[1]. Anna I, Jaroslaw K, 2014. A laboratory method to determine the hydraulic conductivity of mountain forest soils using undisturbed soil samples. Journal of Hydrology, 519: 1649-1659. doi: 10.1016/j.jhydrol.2014.09.045

[2]. Cheng Cheng, Jinxi Song, Xunhon Chen et al., 2011. Statistical distribution of streambed vertical hydraulic conductivity along the Platte River, Nebraska. Water Resources Management, 25: 265285. doi: 10.1007/s11269-010-9698-5

[3]. Chen X H, Shu L, 2002. Stream-aquifer interactions: evaluation of depletion volume and residual effects from ground water pumping. Ground Water, 40(3): 284-290.

[4]. Cheng C, Chen X H, 2007. Evaluation of methods for determination of hydraulic properties in an aquifer-aquitard system hydrologically connected to a river. Hydrogeol Journal, 15: 669-678.

[5]. Chen XH, Song J, Cheng $\mathrm{C}$ et al., 2009. A new method for mapping variability in vertical seepage flux in streambeds. Hydrogeol Journal, 17(3):519-525. doi: 10.1007/s10040-008-0384-0.

[6]. Hvorslev, M. J, 1951. Time lag and soil permeability in ground-water observations.U.S. Army Corps of Engineers, Waterways Experiment Station Bulletin, 36: 1-50. 
[7]. Ibrahimu Chikira Mjemah, Marc Van Camp, Kristine Walraevens, 2009. Groundwater exploitation and hydraulic parameter estimation for a quaternary aquifer in Dar-es-Salaam Tanzania. Journal of African Earth Sciences, 55: 134-146. doi: 10.1016/j.jafrearsci.2009.03.009.

[8]. Lai Wenli, Song Jinxi, Shen Pengyun, 2013. The changes of the vertical hydraulic conductivity of sediments with depth in Weihe River. Journal of Northest University (Natural Science Edition), 43(1): 109-114. (in Chinese)

[9]. Md Rajibul Karim, S.-C. R.Lo, 2015. Estimation of the hydraulic conductivity of soils improved with vertical drains. Computers and Geotechnics, 63: 299-305. doi: 10.1016/j. compgeo.2014.10.010

[10]. Qifei Niu, Ddante Fratta, Yu-Hsing Wang, 2015. The use of electrical conductivity measurements in the prediction of hydraulic conductivity of unsaturated soils. Journal of Hydrology, 522: 475-487. doi: http://dx.doi.org/10.1016/j.jhydrol.2014.12.055.

[11]. Rosa Di Maio, Ester Piegari, Giovanna Todero et al., 2015. A combined use of Archie and van Genuchten models for predicting hydraulic conductivity of unsaturated pyroclastic soils. Journal of Applied Geophysics, 112: 249-255. doi: 10.1016/j.jappgeo.2014.12.002.

[12]. Valentina Carucci, Marco Petitta, Ramon Aravena, 2012. Interaction between shallow and deep aquifers in the Tivoli Plain(Central Italy) enhanced by groundwater extraction: A multiisotope approach and geochemical modeling. Appiled Geochemistry, 27: 266-280. doi: 10.1016/j.apgeochem.2011.11.007.

[13]. Weiwei Jiang, Jinxi Song, Junlong Zhang et al., 2015. Spatial variability of streambed vertical hydraulic conductivity and its relation to distinctive stream morphologies in the Beiluo River, Xhananxi Province, China. Hydrogeology Journal, 23: 1617-1626. doi: 10.1007/s10040015-1288-4.

[14]. Zhang Bo, Song Jinxi, Cao Mingming, 2013. Effect of sediment particle composition on vertical hydraulic conductivity of Weihe River streambed. Bulletin of soil and water conservation, 33(5): 40-44. (in Chinese) 